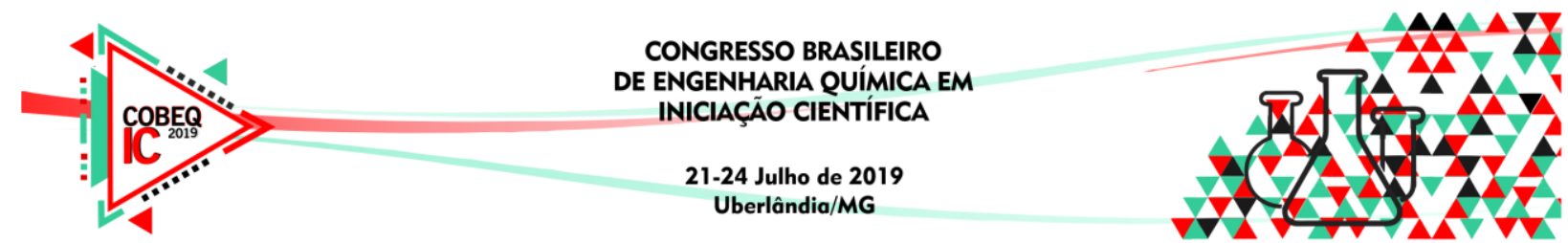

\title{
ANÁLISE DE SOLO TRATADO COM LÍQUIDO PERCOLADO DE COMPOST BARN À BASE DE CASCA DE CAFÉ E DEJETO ORGÂNICO DE BOVINOS
}

\author{
M. A. FONSECA ${ }^{1}$, R. M. GOMES ${ }^{1}$ e D. C. CARVALHO ${ }^{1}$ \\ ${ }^{1}$ Centro Universitário de Patos de Minas - UNIPAM, Faculdade de Engenharia Química \\ E-mail para contato: mateusandradef@hotmail.com; dayenecc@unipam.edu.br
}

\begin{abstract}
RESUMO - Em uma atualidade em que se preza tanto pelo uso consciente dos recursos naturais, pesquisas como esta fazem de suma importância, pois o mesmo faz um estudo da irrigação do solo com e sem o líquido percolado (chorume) do Compost Barn a base da casca de café e dejetos orgânico de bovinos, para averiguar se está havendo a correção das deficiências e melhoria do solo, por meio de análises de NPK, pH, acidez, umidade e matéria orgânica, no solo e no chorume, para evitar o descarte incorreto do efluente no meio ambiente e averiguar se o mesmo está sendo viável, para que possa haver uma diminuição dos gastos com fertilizantes industriais. Com base nos dados obtidos foi montado tabelas e gráficos comparativos, observando a porcentagem de melhoria dos nutrientes do solo irrigado, em comparação com o sem irrigação, que mostrou ser eficaz na melhoria da qualidade do mesmo.
\end{abstract}

\section{INTRODUÇÃO}

Os problemas de degradação ambiental causados por manejo incorreto de dejetos e efluentes orgânicos já são comumente conhecidos pela população, o que acarreta em diminuição da produtividade e qualidade da agricultura do país. O desenvolvimento de práticas e métodos alternativos que foquem a conservação do solo necessitam de uma compreensão científica de seus efeitos em função do tempo. (OLIVEIRA 2004)

A agricultura e a pecuária produzem quantidades de resíduos, como dejetos de animais e restos de culturas, palhas e resíduos agroindustriais, os quais, em alguns casos, provocam sérios prejuízos e problemas de poluição. Todavia, quando manipulados adequadamente, podem suprir aos sistemas agrícolas, boa parte da demanda de insumos sem afetar os recursos do solo e do ambiente (TEIXEIRA, 2002).

O trabalho tem como finalidade fazer um estudo de caso a respeito da irrigação do solo com e sem o líquido percolado (chorume) do Compost Barn a base da casca de café e dejetos orgânico de bovinos, para averiguar se está havendo a correção das deficiências e melhoria do solo, realizando esta verificação por meio de análises químicas, tanto no solo quanto no chorume, para evitar o descarte incorreto do efluente no meio ambiente e reduzir o consumo de fertilizantes com a realização da irrigação utilizando este líquido percolado, o que significaria uma diminuição dos gastos com fertilizantes químicos industriais. 


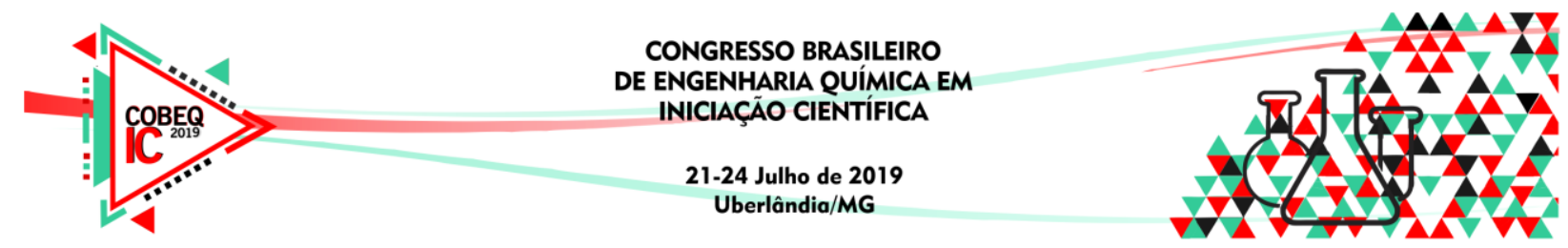

\section{METODOLOGIA}

O presente trabalho foi desenvolvido nos laboratórios de química, de análises de solo e de Engenharia Química do UNIPAM. As amostras são provenientes de um complexo agroindustrial localizada no município de Lagoa Formosa - MG.

São dois tipos de amostra, um fora da área que foi irrigada com o chorume, e as demais em quatro ponto de áreas irrigadas com o mesmo, tendo feito uma média com seus valores. As amostras foram coletadas por três vezes ao decorrer do ano, com 4 meses entre uma coleta e outra. O líquido percolado foi coletado direto da saída do efluente do Compost Barn, sendo este analisado somente uma vez. As amostras sólidas foram armazenadas em sacos de papel Kraft e deixadas secarem ao ar. Antes das amostras secarem, foram retiradas pequenas alíquotas para o teste de umidade. As amostras do chorume foram armazenadas em frasco âmbar e mantidas sob constante refrigeração. As análises de NPK, matéria orgânica, pH e acidez, foram realizadas no solo conforme orientações do órgão regulamentador, Embrapa, 1997. Também foram analisados os níveis de pH, acidez e NPK no liquido percolado.

\subsection{Umidade}

Para o teste de umidade, foi utilizado o aparelho de infravermelho marca Gehaka modelo IV2500, programado para a auto secagem, sem marcação de tempo, com a temperatura em $105^{\circ} \mathrm{C}$, expressando o resultado em porcentagem, leitura direta.

\section{2. pH e acidez}

Foram colocados $10 \mathrm{~mL}$ do solo em um recipiente, juntamente com $25 \mathrm{~mL}$ de solução de $\mathrm{CaCl}_{2}$ 0,01 mol/L que foi agitada e deixada em repouso por 15 minutos. Após, foi agitado em agitador de mesa por 5 minutos, fez-se a leitura no pHmetro. Para acidez, foram colocados $10 \mathrm{~g}$ do solo e $100 \mathrm{~mL}$ de $\mathrm{BaCl}_{2}$ a $0,1 \mathrm{~mol} / \mathrm{L}$ agitando manualmente por 1 minuto, após a agitação a suspensão foi deixada em equilíbrio por uma noite. Em seguida, foram pipetados $50 \mathrm{~mL}$ do sobrenadante para titulação com $\mathrm{NaOH}$ 0,025 mol/L, usando 3 gotas de fenolftaleína como indicador de viragem.

\subsection{Nitrogênio}

Foi feita pelo método de Kjeldahl, que consiste em adicionar $100 \mathrm{mg}$ de amostra no tubo digestor, junto com $1 \mathrm{~g}$ de mistura de sais, $3 \mathrm{~mL}$ de ácido sulfúrico PA e $1 \mathrm{~mL}$ de peróxido de hidrogênio a $30 \%$ e aqueceu-se até $350^{\circ} \mathrm{C}$ até a obtenção de um líquido viscoso esverdeado. Todo o líquido foi transferido, junto com $10 \mathrm{~mL}$ de $\mathrm{NaOH} 40 \%$, para o destilador de Kjeldahl, até completar $45 \mathrm{~mL}$ de extrato, para que ele fosse titulado em $\mathrm{HCl} \mathrm{0,01} \mathrm{mol/L} \mathrm{e}$ usando três gotas do verde de bromocresol como indicador.

\subsection{Fósforo e potássio}

Para as análises de Fósforo e Potássio foi utilizado a Extração com solução de Mehlich 1, também chamada de duplo ácida. Foram adicionados volumes iguais de $\mathrm{HCl}$ a $0,05 \mathrm{~mol} / \mathrm{L} \mathrm{e}$ $\mathrm{H}_{2} \mathrm{SO}_{4}$ a $0,0125 \mathrm{~mol} / \mathrm{L}$. A extração foi feita colocando $10 \mathrm{~cm}^{3}$ da amostra e $100 \mathrm{~mL}$ da 


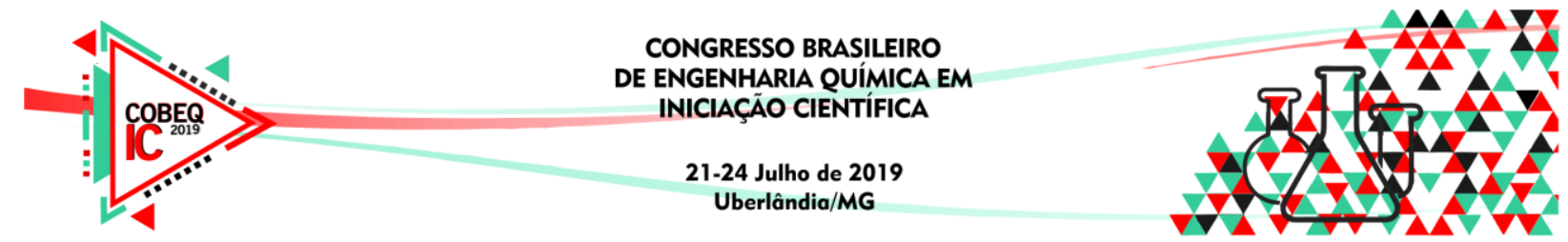

solução extratora, foi deixada por 5 minutos no agitador. Após a decantação por uma noite, foram pipetados, sem filtrar, $25 \mathrm{~mL}$ do extrato para serem reservados para as análises de Fósforo e Potássio. Com a extração já realizada, utilizando a solução extratora de Mehlich 1, o Potássio foi averiguado direto no fotômetro de chama, a partir dos $25 \mathrm{~mL}$ do extrato previamente reservado para o teste. Para fósforo, foram coletados $5 \mathrm{~mL}$ para serem adicionados a $10 \mathrm{~mL}$ de solução ácida de molibidato de amônio diluída e $300 \mathrm{mg}$ de ácido ascórbico em pó. Agitou-se durante dois minutos. A solução ficou reservada por uma hora para que pudesse haver o desenvolvimento de cor. A leitura foi realizada em $660 \mathrm{~nm}$ no espectrofotômetro.

\subsection{Matéria Orgânica}

Método volumétrico pelo bicromato de potássio. Após, foi coletado $0,5 \mathrm{~g}$ do material peneirado para ser adicionado a $10 \mathrm{~mL}$ de solução de bicromato de potássio a $0,2 \mathrm{~mol} / \mathrm{L}$. Adicionou-se um tubo de ensaio de $25 \mathrm{~mm}$ de diâmetro, cheio de água e protegido com papel aluminizado, que funcionou como condensador. Em seguida, foi aquecido em chapa aquecedora, até fervura branda, por 5 minutos. Após o resfriamento, foi adicionado $80 \mathrm{~mL}$ de água destilada, $1 \mathrm{~mL}$ de ácido ortofosfórico e 3 gotas do indicador difenilamina a $10 \mathrm{~g} / \mathrm{L}$ para ser efetuada a titulação com solução de sulfato ferroso amoniacal $0,05 \mathrm{~mol} / \mathrm{L}$.

Para as análises do líquido percolado, mantiveram-se as metodologias, mudando apenas de dados mássicos para volumétricos de amostra

\section{RESULTADOS E DISCUSSÕES}

As amostras foram coletadas a cada 4 meses, sendo três coletas no total, nos meses de fevereiro, junho e outubro do ano decorrente. Na Tabela 1 contém os resultados obtidos para o líquido percolado coletado direto da saída do Compost Barn:

Tabela 1 - Resultados das análises no líquido percolado

\begin{tabular}{|c|c|c|c|c|}
\hline $\mathrm{pH}$ & $\begin{array}{c}\text { Acidez }\left(\mathrm{cmol} \mathrm{de}^{+} \mathrm{e}\right. \\
\left.\mathrm{Al}^{+} / \mathrm{dm}^{3}\right)\end{array}$ & $\begin{array}{c}\text { Nitrogênio }(\mathrm{g} \text { de } \\
\left.\mathrm{NH}_{4} / \mathrm{dm}^{3}\right)\end{array}$ & Fósforo $\left(\mathrm{mg} / \mathrm{dm}^{3}\right)$ & Potássio $\left(\mathrm{g} / \mathrm{dm}^{3}\right)$ \\
\hline 7,33 & 1,13 & 9,94 & 9,90 & 28,10 \\
\hline
\end{tabular}

$\mathrm{O}$ pH encontrado para o chorume foi de 7,33, que é dentro do resultado encontrado por Bouda et al. (2000). Para a acidez, o valor está dentro da faixa obtida por Ribeiro et al, (2010), que obteve $1,1 \mathrm{cmol}$ de $\mathrm{H}^{+}$e $\mathrm{Al}^{3+} / \mathrm{dm}^{3}$ de amostra no solo.

$\mathrm{Na}$ análise nitrogênio total de Kjeldahl e de fósforo foram averiguados os valores muito abaixo dos encontrados por Tavares (2011) em chorume de aterro sanitário que são 94,48 e 22,96 respectivamente, comparado com as amostras de solo, o liquido percolado tem uma maior concentração de $\mathrm{P}$ e $\mathrm{N}$, o que pode ser justificado pela urina dos bovinos, que contem uréia e fosforo inorgânico, que é de 6 a 17,5 mmol de $\mathrm{NH}_{3} / \mathrm{L} \mathrm{e} \mathrm{1,60} \mathrm{a} \mathrm{2,26} \mathrm{mmol} \mathrm{de} \mathrm{P/L,}$ respectivamente, ainda segundo estudo de Bouda et al. (2000).

Já na Tabela 2, contém os resultados obtidos nas três coletas, com as amostras de solo com e sem a irrigação do líquido percolado. 


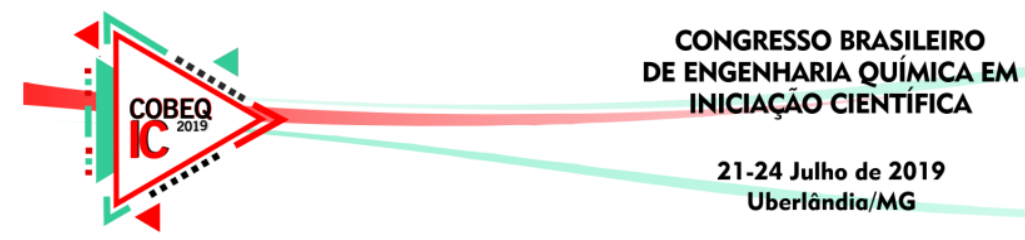

Tabela 2 - Resultados das amostragens do solo com e sem irrigação para as três coletas.

\begin{tabular}{|c|c|c|c|c|c|c|}
\hline Coletas & \multicolumn{2}{|c|}{1} & \multicolumn{2}{|c|}{2} & \multicolumn{2}{c|}{3} \\
\hline Nutrientes & $\begin{array}{c}\text { Sem } \\
\text { Chorume }\end{array}$ & $\begin{array}{c}\text { Com } \\
\text { Chorume }\end{array}$ & $\begin{array}{c}\text { Sem } \\
\text { Chorume }\end{array}$ & $\begin{array}{c}\text { Com } \\
\text { Chorume }\end{array}$ & $\begin{array}{c}\text { Sem } \\
\text { Chorume }\end{array}$ & $\begin{array}{c}\text { Com } \\
\text { Chorume }\end{array}$ \\
\hline Umidade (\%) & 19,77 & 24,45 & 18,50 & 22,28 & 18,94 & 22,99 \\
\hline $\mathrm{pH}$ & 4,73 & 5,24 & 5,06 & 5,22 & 4,91 & 5,31 \\
\hline Acidez $\left(\mathrm{cmol} \mathrm{de} \mathrm{H}^{+} \mathrm{e} \mathrm{Al}^{+} / \mathrm{dm}^{3}\right)$ & 0,40 & 0,27 & 0,28 & 0,20 & 0,80 & 0,27 \\
\hline Nitrogênio $\left(\mathrm{g} \mathrm{de} \mathrm{NH}_{4} / \mathrm{dm}^{3}\right)$ & 2,10 & 2,88 & 2,49 & 3,79 & 1,91 & 3,02 \\
\hline Fósforo $\left(\mathrm{mg} / \mathrm{dm}^{3}\right)$ & 3,80 & 3,77 & 5,03 & 12,78 & 4,97 & 8,37 \\
\hline Potássio $\left(\mathrm{mg} / \mathrm{dm}^{3}\right)$ & 16,86 & 37,03 & 15,60 & 26,77 & 15,51 & 35,64 \\
\hline Matéria Orgânica $(\mathrm{g} / \mathrm{kg})$ & 34,90 & 35,45 & 25,88 & 31,22 & 25,32 & 31,42 \\
\hline
\end{tabular}

Nos resultados obtidos de umidade pode-se observar que a amostra sem irrigação do líquido percolado apresenta menor umidade do que as demais amostras que são irrigadas. Já os resultados de $\mathrm{pH}$ e acidez também se obteve a comprovação que o chorume melhora o solo nestes aspectos, visto que neutraliza um pouco do baixo $\mathrm{pH}$ e diminui níveis de acidez, deixando o solo perto do recomendado para o plantio de grãos que é de $0,2 \mathrm{cmol} \mathrm{de}^{+} \mathrm{e} \mathrm{Al}^{3+}$ $/ \mathrm{dm}^{3}$, segundo Novais et al. (2007).

Os valores obtidos para quantidade de potássio foram positivos pelo aumento com a irrigação com o liquido percolado passando de 16,86 até $37,03 \mathrm{~g} \mathrm{de} \mathrm{K} / \mathrm{dm}^{3}$, assim como os valores de fosforo que foi de 3,80 até $12,78 \mathrm{mg} \mathrm{de} P / \mathrm{dm}^{3}$, e também os valores de nitrogênio, que aumentaram de 2,10 para até $3,79 \mathrm{~g}$ de $\mathrm{NH}_{4} / \mathrm{kg}$ de amostra, resultado semelhante ao de Freixo et al. (2002) para a amostra sem irrigação, que foi de $1,71 \mathrm{~g}$ de $\mathrm{NH}_{4} / \mathrm{kg}$ de amostra.

Os valores de matéria orgânica obtidos ficaram abaixo do encontrado por Freixo et al. (2002) que foi de 46,8 g de matéria orgânica por $\mathrm{kg}$ de amostra em solos do cerrado a uma altura de 0 a $5 \mathrm{~cm}$, que pode ser explicado pela diferença de altura de coleta da amostra, uma vez que este trabalho foi realizado em amostras de 0 a $20 \mathrm{~cm}$.

A tabela 3, contém os valores de porcentagem (\%) de redução da acidez do solo, nas três coletas, em comparação com o ponto sem irrigação de líquido percolado.

Tabela 3 - Porcentagem de redução da acidez do solo irrigado

\begin{tabular}{|c|c|}
\hline Coletas & Porcentagem de redução de acidez (\%) \\
\hline 1 & 31,25 \\
\hline 2 & 29,70 \\
\hline 3 & 66,25 \\
\hline
\end{tabular}

A redução da acidez do solo foi perceptível desde as primeiras semanas, tendo na terceira coleta a melhor porcentagem de redução dos níveis de acidez, com $66,25 \%$ de redução em comparação com a amostra de solo não irrigada com o chorume.

No gráfico 1, são apresentados os valores de umidade, $\mathrm{pH}$ e matéria orgânica com suas porcentagens de aumento nas três coletas realizadas. 


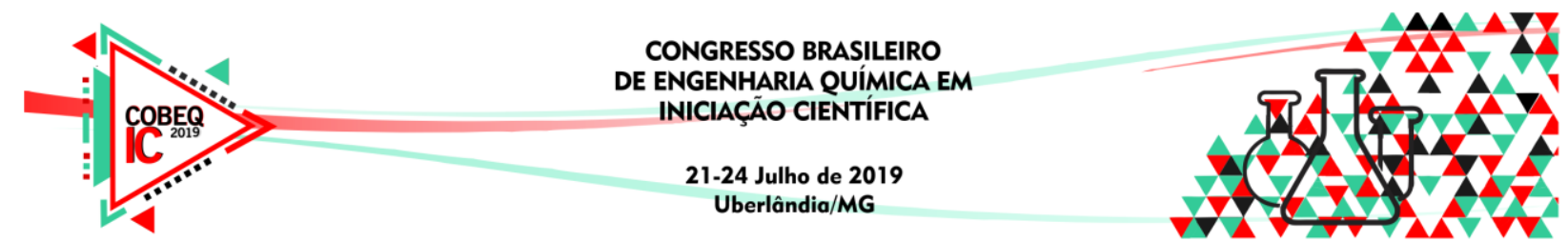

Gráfico 1 - Porcentagem de aumento dos níveis de umidade, pH e matéria orgânica do solo.

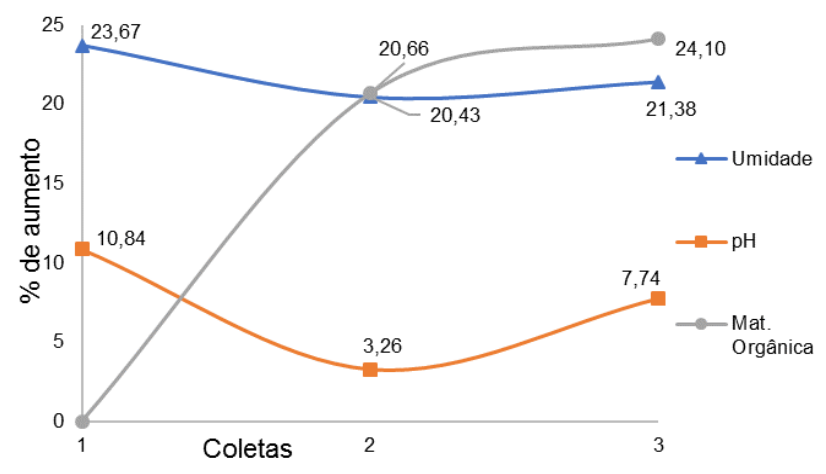

Observa-se que desde a primeira coleta houve um aumento da umidade do solo, que se manteve na faixa dos $20 \%$ de aumento até a última coleta, tendo o valor mais baixo de aumento na segunda coleta, que coincidiu com a época de estiada da região sudeste. Para o pH também houve aumento, começando com $10,84 \%$ na primeira coleta, diminuindo, na segunda para $3,26 \%$ de aumento e finalizando com $7,74 \%$ na terceira coleta.

Os valores de matéria orgânica, houve melhora com o decorrer do tempo de irrigação, que pode ser explicado pelas rotas de formação de substâncias húmicas (SU), que segundo Novais et al. (2007), advém da degradação da lignina pelos microrganismos por isso, para a mesma não foi observada melhora na primeira amostragem, pois não houve tempo suficiente para que a lignina fosse degradada. Este foi finalizando com o valor de 24,10\% de aumento.

Abaixo, no gráfico 2, são mostrados os valores das porcentagens de aumento para os níveis de NPK no solo irrigado com o líquido percolado em comparação com o não irrigado.

Gráfico 2 - Análises de aumento dos níveis de NPK do solo irrigado.

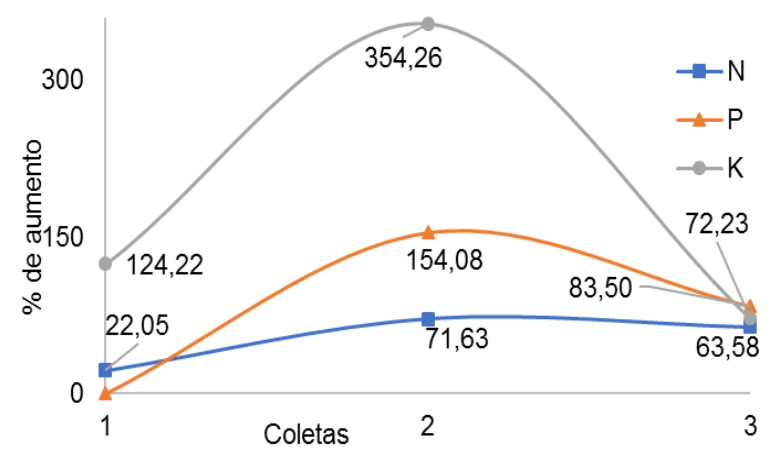

Conforme apresentados os valores, nota-se que para nitrogênio e potássio, houve melhora desde a primeira coleta, com valores de porcentagem de aumento de $22,05 \%$ para $\mathrm{N}$ e $124,22 \%$ para K, diferente do ocorrido para os resultados de fósforo, que assim como os níveis de matéria orgânica, só foi possível observar aumento dos valores, a partir da segunda coleta, que pode ser justificado, segundo Novais et al. (2007), pela mineralização do P, pois boa parte do que é adicionada aos solos é retida como uma energia tal que seu equilíbrio com o P-solução desaparece, formando o $\mathrm{P}$ não-lábil, além da rápida adsorção do nutriente pelo 


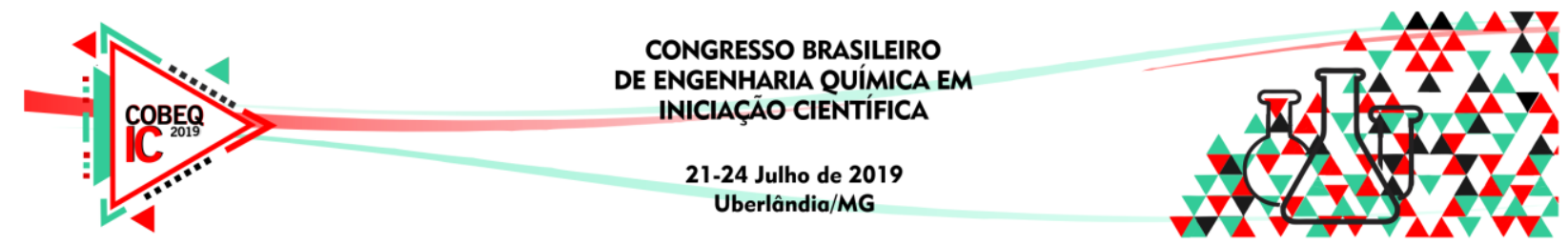

solo, o que faz com que ele fique pouco tempo disponível no solo, não permitindo a dessorção de $\mathrm{P}$, o que pode justificar o não aumento da concentração de fósforo na primeira coleta.

No entanto, pode-se observar que alguns níveis de nutrientes no solo, mesmo que tenham sidos irrigados periodicamente, não obtiveram uma crescente melhora, da primeira até a última coleta, o que poderia indicar uma inconstância na irrigação, pois as datas não são fixas, além da quantidade de chorume despejada em determinado ponto da área a ser coletada amostra não ser precisamente a mesa nas demais irrigações, ou seja, alguns pontos podem estar recebendo mais chorume do que outros.

\section{CONCLUSÕES}

Baseado nos resultados obtidos na realização deste trabalho, pode-se observar que a irrigação do solo com o líquido percolado do Compost de Barn foi benéfica ao solo, visto que o mesmo melhora os níveis de umidade, $\mathrm{pH}$, acidez, nitrogênio, potássio e matéria orgânica, em comparação com os valores das amostras que não foram irrigadas com o chorume.

Portanto, a irrigação das áreas amostradas com o chorume foi benéfico e pode ser realizado com o intuito de diminuição de custos na fertilização química industrial, pois aumentou significamente os níveis de nutrientes avaliados, deixando próximos, em sua maioria, do encontrado nas literaturas.

\section{REFERÊNCIAS}

BOUDA, J.; QUIROZ-ROCHA, G. F.; GONZÁLEZ, F. H. D.; Importância da Coleta e Análise de Líquido Ruminal e Urina. Gráfica da Universidade Federal do Rio Grande Do Sul. Porto Alegre, Brasil, 2000.

FREIXO, A. A.; MACHADO, P. L. O. A.; GUIMARÃES, C. M.; SILVA, C. A.; FADIGAS, F. S. Estoques De Carbono E Nitrogênio E Distribuição De Frações Orgânicas De Latossolo Do Cerrado Sob Diferentes Sistemas De Cultivo. Revista Brasileira de Ciência do Solo, vol. 26, núm. 2, 2002, pp. 425-434. SBCS. Viçosa, Brasil.

NOVAIS, R. F. et al.; Fertilidade do Solo. Sociedade Brasileira de Ciência do Solo. Cap. X, XI, XII, XIII e IX. 1 ${ }^{a}$ Edição, 1017 p - Viçosa - MG, 2007.

OLIVEIRA, Francisco Nelsieudes Sombra. Uso da Compostagem em Sistemas Agrícolas Orgânicos. Embrapa, Fortaleza - CE, p.1-17, 2004.

RIBEIRO, R. S.; ALVES, T. F.; SOUZA, J. E. S.; BRANDÃO, G. O.; Alterações físicoquímicas provocadas pelo chorume em latossolos no cerrado do brasil central. Anuário Da Produção De Iniciação Científica Discente Vol. 13, N. 20. Faculdade Anhanguera de Brasília - Unidade Taguatinga. Ano 2010.

TAVARES, F. D. T.; Tratamento de chorume: Análise dos efluentes da evaporação forçada. Universidade Federal do Rio de Janeiro. 2011. 


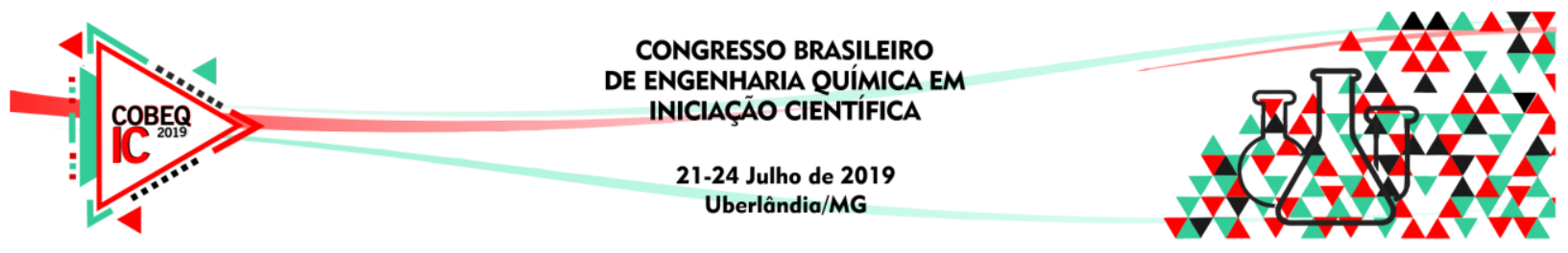

TEIXEIRA, R.F.F. Compostagem. In: HAMMES, V.S. (Org.) Educação ambiental para o desenvolvimento sustentável. Brasília: Embrapa Informação Tecnológica, 2002, v.5, p.120-123. 